\title{
Weight status and body image perceptions in adolescents: current perspectives
}

REVIEW

This article was published in the following Dove Press journal:

Adolescent Health, Medicine and Therapeutics

25 August 2015

Number of times this article has been viewed

\section{Dana K Voelker' \\ Justine J Reel ${ }^{2}$ \\ Christy Greenleaf ${ }^{3}$}

'West Virginia University, College of Physical Activity and Sport Sciences, Morgantown, WV, ${ }^{2}$ University of North Carolina Wilmington, College of Health and Human Services, Wilmington, $\mathrm{NC},{ }^{3}$ University of Wisconsin-Milwaukee, College of Health Sciences, Milwaukee, WI, USA

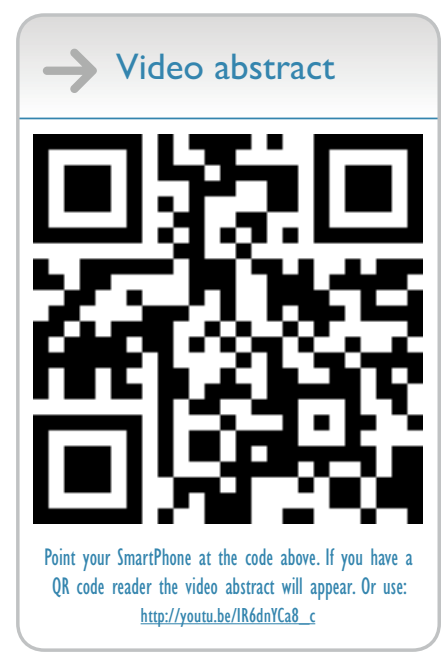

Correspondence: Dana K Voelker Department of Sport Sciences, West Virginia University, Health and Education Building, CPASS 207, PO Box 6116, 375 Birch Street, Morgantown, WV 26506-6II6, USA Tel + I 304293087 I

Email dkvoelker@mail.wvu.edu

\begin{abstract}
Adolescence represents a pivotal stage in the development of positive or negative body image. Many influences exist during the teen years including transitions (eg, puberty) that affect one's body shape, weight status, and appearance. Weight status exists along a spectrum between being obese (ie, where one's body weight is in the 95th percentile for age and gender) to being underweight. Salient influences on body image include the media, which can target adolescents, and peers who help shape beliefs about the perceived body ideal. Internalization of and pressures to conform to these socially prescribed body ideals help to explain associations between weight status and body image. The concepts of fat talk and weight-related bullying during adolescence greatly contribute to an overemphasis on body weight and appearance as well as the development of negative body perceptions and dissatisfaction surrounding specific body parts. This article provides an overview of the significance of adolescent development in shaping body image, the relationship between body image and adolescent weight status, and the consequences of having a negative body image during adolescence (ie, disordered eating, eating disorders, and dysfunctional exercise). Practical implications for promoting a healthy weight status and positive body image among adolescents will be discussed.
\end{abstract}

Keywords: adolescence, eating disorders, obesity, bullying, puberty, physical activity

\section{Weight status and body image perceptions in adolescents: current perspectives}

Body image has become a popular topic over the past 35 years. In fact, $90 \%$ of body image studies have been published since $1980 .{ }^{1}$ Interest in this area parallels growing public health concerns about weight status, physical inactivity, obesity, eating disorders, and the associated spectrum of health consequences. Body image is a multidimensional construct encompassing how we perceive, think, feel, and act toward our bodies ${ }^{2}$ and lies on a continuum from healthy body perceptions (ie, accurate and mostly positive) to unhealthy body perceptions (ie, inaccurate and mostly negative). ${ }^{3,4}$ Evidence consistently indicates that unhealthy body image is associated with obesity and physical inactivity ${ }^{5}$ and plays a pivotal role in the development of eating disorders during adolescence. ${ }^{6}$ Importantly, body image has "developmental significance" such that it is not a static personal characteristic, but rather a dynamic aspect of ourselves that changes over the lifespan. ${ }^{1}$ Adolescence represents a critical period for healthy body image development due to the type and magnitude of age-related transitions occurring during this time. This paper will discuss the relevant literature on the significance of adolescent development in shaping body image, the relationship between body image and adolescent weight status, and the consequences of an unhealthy body image during 
adolescence. Intervention strategies that address adolescent weight status and body image will be discussed.

\section{Adolescence as a critical period in body image development}

A variety of cultural, social, physical, and psychological changes that characterize adolescence uniquely interact to shape body image between the ages of 12 years and 18 years. Our appearance-oriented culture often targets teens as potential consumers and has a significant negative impact on their body image. In their meta-analysis, Groesz et $\mathrm{al}^{7}$ found that the greatest decline in body satisfaction occurred in girls under the age of 19 following exposure to overtly thin media images. Recent studies indicate that current diet, exercise, and beauty trends displayed in reality television shows and social media outlets can contribute to unhealthy adolescent body perceptions. For example, Ashikali et $\mathrm{al}^{8}$ found that 15-18-year old girls exposed to a cosmetic surgery show (ie, Dr 90210) reported more weight-related and appearance dissatisfaction than a control group exposed to a home improvement show (ie, Extreme Makeover Home Edition). Tiggemann and Slater ${ }^{9}$ found that among 13-15-year old girls, body image concerns increased with time spent on the Internet and Facebook usage. Meier and Gray ${ }^{10}$ further identified that the time spent on Facebook was less important than the degree of exposure to appearance-specific media such as photo sharing, which was positively associated with body image concerns. These findings suggest that in addition to print media, current television and Internet trends are sources of promoting unrealistic and so-called ideal images to adolescents. As a continually evolving and ubiquitous source of information on body ideals, Perloff ${ }^{11}$ calls for more research on the Internet, social media, and their influence on body image among adolescents.

These cultural ideals and beliefs are also reinforced by significant others in adolescents' immediate environments, including family, peers, and romantic partners. Relative to family, research has shown that weight-based teasing from parents and siblings is associated with body dissatisfaction among girls and drive for muscularity among boys in eighth and ninth grade. ${ }^{12}$ In a longitudinal study, Helfert and Warschburger ${ }^{13}$ found that the encouragement from parents to control weight was also linked to heightened weight concerns among high school girls and boys. Further, negative weight talk and dieting among family members, especially from mothers who serve as role models for body image, has been shown to be related to body image concerns and disordered eating behaviors in adolescent girls. ${ }^{14}$ Peers have also been identified as a prominent source of weight- and appearancebased pressures. In their systematic review, Webb and Zimmer-Gembeck ${ }^{15}$ found that friends and peers influence adolescent body dissatisfaction through various mechanisms, including appearance-based teasing and criticism, modeling and discussing appearance concerns, making appearance comparisons, judging the appearance of friends, and social conflict or exclusion. Although less studied, romantic relationships also influence adolescent body image. For example, Paxton et al $^{16}$ found that body dissatisfaction among tenth grade girls was strongly predicted by the belief that thinness was critical to their attraction to boys. Further, $85 \%$ of boys did indeed perceive thinness as an attractive quality in girls. How adolescents perceive their bodies is strongly influenced by their larger sociocultural context.

Importantly, the influence of body ideals interacts with a critical period of physical change during adolescence as well. Specifically, the changes that occur during puberty are among the most rapid and diverse in human development, including changes in weight, height, body shape, body composition, as well as primary and secondary sex characteristics. Importantly, these physical changes also coincide with heightened exposure and subsequent comparisons to cultural ideals of beauty. For girls, cultural expectations emphasize being thin and lean with large breasts as seen in print media, television, and online. Thus, changes associated with puberty, such as increases in adiposity and widening of the hips, may be perceived negatively and seen as incongruent with the prototypical and societally valued "thin ideal." Early maturing girls in particular, who are prone to greater puberty-related weight gain, ${ }^{17}$ have reported a greater drive for thinness and stronger preference for a slender figure than their later maturing counterparts. ${ }^{18}$ This finding suggests that early maturing girls may be especially vulnerable to developing a negative body image when they perceive their changing bodies to be misaligned with cultural ideals. Although evidence indicates that adolescent boys report greater weight and appearance esteem than girls, ${ }^{19}$ boys are not immune to body image concerns during adolescent development. Specifically, increases in height and muscle mass associated with puberty moves some boys closer to cultural expectations to be tall and muscular. Late-maturing boys specifically, who have not achieved socially constructed body ideals for men, report greater body dissatisfaction than their early maturing counterparts. ${ }^{20}$ Thus, the perception of physical changes in a sociocultural context plays a critical role in shaping body image throughout adolescence.

From a psychological perspective, adolescence has been identified as a period of identity development in which they 
explore possible selves and make significant life decisions that inform aspects of their lives, ${ }^{21,22}$ including ideological (ie, occupation, religion, politics, values) and interpersonal domains (ie, family, friendships, romantic partnerships, and gender roles). ${ }^{23}$ Although an underexplored area, preliminary evidence suggests that these identity development processes are linked to body image. In a study of late-adolescent Swedish youth, Wängqvist and Frisén ${ }^{24}$ found that girls with stronger interpersonal identity commitments also had more positive views of how others evaluated their appearance. Similarly, boys with stronger interpersonal identity commitments evaluated their own appearance more favorably. These findings suggest that body image may improve as adolescent's sense of self becomes increasingly stabilized. Other research indicates that adolescents who strongly identify with traditional gender roles may invest more in media-based body ideals. ${ }^{25}$ Further investigation will help us to understand the critical role of adolescent identity exploration and commitment in shaping body perceptions.

\section{The relationship between adolescent weight status and body image}

The percentage of obese adolescents has quadrupled over the past 30 years. ${ }^{26}$ Recent estimates indicate that $\sim 17 \%$ or 12.7 million youths ages 2-19 years are obese in the US, with higher prevalence rates found among Hispanic youth $(22.4 \%)$, followed by non-Hispanic black (20.2\%), white (14.1\%), and Asian youth (8.6\%). Over the course of childhood and adolescence, obesity prevalence increases (ie, $8.4 \%$ of $2-5$-year olds, $17.7 \%$ of $6-11$-year olds, and $20.5 \%$ of $12-19$-year olds), ${ }^{26}$ which is of considerable concern for health and wellness over the lifespan.

Importantly, the weight status of youth (ie, overweight and obese) is strongly connected to body image. Specifically, research consistently shows that greater body mass index (BMI) is associated with heightened weight concerns in both adolescent girls and boys. ${ }^{27,28}$ Longitudinal studies suggest that the impact on body image are long-term such that greater BMI during adolescence strongly predicts body dissatisfaction in young adulthood. ${ }^{29,30}$ However, while the association between weight status (objective or perceived) and body image is relatively consistent in the literature, the varied psychological factors that contribute to that relationship provide a more complex picture. Internalization, the degree to which someone adopts a sociocultural body ideal as his or her own, ${ }^{31}$ seems to be a particularly salient psychological factor in the weight status-body image relationship.
For example, in a direct test, Nanu et a ${ }^{19}$ found support for the influence of internalization on the association between BMI and appearance- and weight-related esteem among girls aged 15-20 years. Lawler and Nixon ${ }^{32}$ in a study that included 111 boys and 129 girls between the ages of 12 and 19, also supported internalization as a key construct. Internalization, along with appearance criticism and conversations with peers, accounted for $45.7 \%$ of variance in body dissatisfaction over and above BMI. Additionally, Knauss et $\mathrm{al}^{33}$ reported that among 819 boys and 791 girls aged 14-16, internalization of body ideals represented in the media and perceived pressures to conform to those ideals were significant predictors of body dissatisfaction after accounting for BMI. For girls in the study, the strongest predictor of body dissatisfaction was internalization. These results together suggest that the degree to which unrealistic body ideals are adopted as one's own impacts the strength of the relationship between body mass and body image.

There are exceptions to studies that support internalization as a key construct in explaining the associations between weight status and body image. Petrie et al, ${ }^{34}$ for example, considered the relative contributions of various biological, psychological, and social variables (eg, BMI, pubertal development, pressures, internalization, social comparison, physical fitness, physical self-concept, depression, and selfesteem) to body image among 629 boys and 659 girls in grades 6-8. After accounting for BMI and pubertal development, girls with higher BMI, greater perceived pressure to attain a lower weight, stronger social comparison, poorer perceptions of physical ability, and higher self-esteem had greater satisfaction with their bodies. For boys, stronger perceived pressures to gain muscle and poorer physical selfconcept predicted body satisfaction above and beyond BMI. Internalization, although correlated with both BMI and body satisfaction (among girls only), was not a significant predictor of satisfaction for boys or girls. Looking at similar types of associations, Mitchell et al, ${ }^{35}$ in a study of 685 girls in grades 6-8, took a slightly different approach and examined BMI as a possible moderator of the association between internalization and body dissatisfaction. BMI was associated with both variables but did not moderate the relationship. It is likely that because of the complex, multifaceted, and dynamic nature of social and psychological influences, multiple factors must be considered. It may be that for some adolescents, other variables, such as pressures and concerns, social comparison, and weight-related talk and bullying, override the influence of internalization of social body ideals on the weight statusbody image relationship. 
Indeed, appearance- and weight-related concerns and pressures mediate associations between body weight/ BMI and body image. Weight concerns and pressures are experienced when individuals worry about their weight or physique, such as believing that their body is too fat or not muscular enough, and perceive that others also believe that their body shape or size is unacceptable. Jones and Crawford, ${ }^{36}$ in a study of 128 boys in grades $8-11$, found that BMI was negatively associated with lack of muscularity concerns and positively associated with thinness concerns; both muscularity and thinness concerns were, in turn, positive predictors of body dissatisfaction. Thus, concerns about not being muscular enough and being overweight, which are consistent with dominant body ideals for males, partially accounted for variance in the relationship between body mass and body dissatisfaction. Knauss et $\mathrm{al}^{33}$ and Petrie et $\mathrm{al}^{34}$ also supported weight pressures as a significant predictor of body-related satisfaction beyond BMI. Petrie et al found that perceived pressure to gain muscularity was a predictor for boys; for girls, on the other hand, pressure to lose weight was significant. Both studies found associations between internalization and pressures, although Petrie et al did not find internalization to predict body satisfaction. Taken together, these results indicate that perceived pressures may outweigh the influence of internalization of social body ideals as a predictor of body image.

Other factors contributing to the complex relationship between weight status and body image include social influences, such as social comparison, fat talk, and weight-related bullying. Social comparison, which is the tendency to compare one's body or physique to that of others (ie, often someone within a peer or friendship group), is especially relevant among adolescents. Myers and Crowther, ${ }^{37}$ in a meta-analytic review of 156 studies, found that the effect of social comparison on body dissatisfaction was negatively related to age, which supported the contention that comparing one's body to others is particularly problematic during adolescence. Petrie et $\mathrm{a}^{34}$ found that engaging in social body comparison contributed to variance in body satisfaction among girls above and beyond what was accounted for by BMI. Similarly, Rodgers et $\mathrm{al}^{38}$ studied 488 girls with a mean age of 12.35 years and found that $86 \%$ of body image concerns were accounted for by a model that included BMI and social comparison along with peer teasing and internalization. Interestingly, social comparison and internalization mediated the effects of social influences, but not BMI, on body image. Thus, although body size, as indicated by BMI, may contribute to body image, it is perception (eg, internalization, pressures, social comparison) that appears to play a key role in adolescents' assessment of their bodies.

Fat talk, defined as negative body- and weight-related comments or conversations, is associated with body dissatisfaction among adolescents, ${ }^{39}$ yet research exploring the extent to which fat talk influences the weight status-body image relationship is limited. Bauer et $\mathrm{al}^{40}$ studied 218 mother-daughter pairs. Mothers' scores on a measure of fat talk that assessed frequency of talk directed toward their daughters, themselves, and others were associated with body dissatisfaction among their daughters. These findings held even after accounting for BMI, which indicates that fat talk may be associated with dissatisfaction independent of weight status.

A construct associated with fat talk is weight-related bullying, which can include behavioral, psychological, and relational components, such as teasing and social exclusion. Overweight and obese youth are more likely to be the targets of weight-related bullying. In a meta-analysis of 30 studies, van Geel et $\mathrm{l}^{41}$ found that overweight youth are 1.19 and obese youth 1.15 times more likely to be bullied compared to normal weight peers. Experiences of bullying are associated with weight dissatisfaction. Lampard et $\mathrm{al}^{42}$ examined weight-related teasing as a school level variable, defined as the proportion of adolescent participants who reported individual teasing at each school, among 20 middle and high schools. Results from their study indicated that higher levels of girls' body dissatisfaction were related to higher prevalence of school level teasing. Adolescents who experience weightrelated bullying report negative affect, such as sadness and depressed mood, as a result. ${ }^{43}$ Moreover, Fox and Farrow ${ }^{44}$ found that esteem (global and physical) and body dissatisfaction mediated the relationships between weight status and victimization among 195 boys and 175 girls aged 11-14 years. Thus, overweight and obese youth may be particularly vulnerable to experiencing weight-related bullying when they also experience lower esteem and higher body dissatisfaction.

\section{Weight status, body image, and the impact on health behaviors}

The complex relationship between weight status and body image is important because of its influence on adolescents' health behaviors. Negative health consequences that may result from the unique interaction of weight status and body image include physical inactivity, eating disorders, and dysfunctional exercise. 


\section{Physical inactivity}

Trends in the prevalence of physical activity among overweight and obese, compared to normal weight peers, are not clear. Whitt-Glover et al, ${ }^{45}$ for example, examined 2003-2004 National Health and Nutrition Examination Survey (NHANES) data and did not find major differences in meeting physical activity recommendations as a function of weight status. Belcher et al, ${ }^{46}$ however, found that normal weight youth engaged in 16 more minutes of moderate or vigorous physical activity compared to obese peers. Janssen et a ${ }^{47}$ reviewed data from 34 countries and found that higher BMI was associated with lower levels of physical activity among 10-16-year olds. It is likely that other factors, such as age, gender, race/ethnicity, and socioeconomic status, also interact with body image and related constructs to influence physical activity levels.

Overweight and obese youth, especially those who have body- and appearance-related concerns, are likely to avoid physical activity. For example, Neumark-Sztainer et al ${ }^{48}$ in a study of 2,516 adolescents found negative associations between body satisfaction and physical activity. Similarly, Puhl and Luedicke ${ }^{43}$ found that among adolescents who were bullied, those who experienced negative affect avoided physical activity. The intersectionality of weight, feelings about one's body, and barriers to activity were highlighted in a systematic review of 15 qualitative research studies focused on physical activity. ${ }^{49}$ Specifically, common themes reported across studies indicated that overweight and obese youth perceive individual barriers (eg, lack of fitness associated with excess weight), social barriers (eg, exclusion and teasing), and environmental barriers (eg, lack of privacy in gym changing rooms). To extend previous work, Greenleaf et al ${ }^{50}$ examined physical fitness in addition to self-concept, self-efficacy, and physical activity. Their study included 1,419 middle school students, and results indicated that after accounting for BMI, gender, ethnicity, socioeconomic status and pubertal development, adolescents who had experienced teasing reported lower physical self-concept and physical activity self-efficacy. In addition, cardiorespiratory fitness and upper body strength were lower among adolescents who had been teased even though no differences in self-reported physical activity were found. The association between weight status, weight stigma experiences, and physical activity seem fairly clear; yet, additional research is needed to better understand the mechanisms underlying these associations and to further explore the impact on physical fitness.

The influence of gender on the consequences of the weight status-body image relationship is somewhat unclear.
Losekam et $\mathrm{al}^{51}$ found that greater weight teasing was associated with lower levels of physical activity among boys; however this relationship was not significant among girls. In contrast, Jensen and Steele ${ }^{52}$ reported that among girls with higher body dissatisfaction, weight-related criticism was associated with lower levels of physical activity; however, this association was not found among boys with higher body dissatisfaction. Although male and female adolescents experience pressures to conform to lean body ideals, there seems to be greater social stigma and stronger psychosocial consequences for females. The extent to which the social construction of gender and body ideals shapes physical activity, in association with weight status and body image must be further studied to identify consistent patterns.

The negative associations between weight, body image, and physical activity are unfortunate given that the positive effects of engaging in physical activity on body image, with and without changes in body composition, are consistently demonstrated in the literature. ${ }^{53-56}$ Yet, many young people likely experience a cycle of weight concerns, physical activity avoidance, pathogenic weight control behaviors, weight gain and experiences of weight-related bias and stigma.

\section{Eating disorders and dysfunctional exercise}

Body image concerns for adolescents extend beyond vanity and attitudes about appearance. Body dissatisfaction among adolescent samples has been consistently shown to be the strongest predictor of disordered eating behaviors and clinical eating disorders across psychosocial variables, such as perfectionism and locus of control. ${ }^{57}$ Negative body image among adolescents, which includes dissatisfaction with one's body shape, size, or specific body part and body distortion (ie, feelings that one is larger than actual size), can directly impact eating behaviors in an attempt to sculpt one's body into a perceived ideal and gain a sense of control. ${ }^{58}$

The link between body dissatisfaction and the development of disordered eating have been explained by the reduced self-esteem and negative emotions, such as depression, that tend to occur when body dissatisfaction is present, but these mediators have received equivocal results across studies. ${ }^{59}$ Therefore, recent studies have attempted to examine the relationship between the importance of body image (ie, salience attached to attaining the ideal body) and disordered eating behaviors versus the effect of body dissatisfaction alone. These initial findings suggest that the connection between body image disturbances and disordered eating 
behaviors is complex and does not represent a direct, linear relationship. ${ }^{60}$ More research is needed to explain why body dissatisfaction is a consistent predictor of the development of clinical eating disorders and disordered eating behaviors.

Negative body image has been a central diagnostic feature for all clinical eating disorders (ie, anorexia nervosa, bulimia nervosa, binge eating disorder) as outlined by the Diagnostic and Statistical Manual of Mental Disorders, Fifth Edition (DSM-5). ${ }^{61}$ Although all eating disorder diagnoses have included criteria about body image disturbances in the way one's shape or weight is experienced, symptoms are manifested differently for each disorder. Anorexia nervosa involves the severe restriction of food intake to unhealthy levels that results in caloric deprivation. By contrast, bulimia nervosa is characterized by binge episodes of overeating followed by compensatory purging, such as vomiting, laxatives use, diuretics, or obligatory exercise to counteract excessive caloric intake. ${ }^{61}$ This obligatory exercise goes beyond what is considered "healthy exercise" and features feelings of compulsion, guilt, and rigidity with regards to what "counts" as exercise. ${ }^{62}$ This exercise may serve as a way to compensate for calories consumed and an attempt to cope with feelings of guilt and negative body image. ${ }^{63}$ Finally, binge eating disorder, a new classification in the DSM-5, features binge episodes without an accompanying purging method. Shame and harsh self-criticism have been identified as underlying mechanisms for binge eating behavior. ${ }^{64}$

Adolescent girls face considerable risk for the development of clinical eating disorders due to intense body dissatisfaction and pressure from peers to "look" a particular way; however, disordered eating and dieting behaviors that do not meet full clinical criteria for eating disorder diagnoses are much more common. ${ }^{65}$ Dieting is popular among teens and college students who embrace the latest fad (eg, Paleo diet) in an attempt to overcome desires (eg, to consume sugar) that may interfere with weight-related goals. ${ }^{66}$ Adolescents may initially choose to diet or restrict food intake (ie, dietary restraint) in attempts to change weight or size. They may also develop pathogenic methods for purging food that lead to unintended health consequences. Furthermore, adolescents who experience guilt following a binge episode may impulsively respond by vomiting, excessively exercising, or using laxatives. Adolescents who view purging behavior as a "workaround" for dietary setback may experience the addictive quality of the purge when they feel temporary emotional relief. This "temporary solution" can ultimately reach clinical levels if the behavior continues for several months on a consistent basis. Disordered eating is often distinguished from clinical eating disorders as being pathological while not meeting all of the DSM-5 criteria. ${ }^{61}$ In some cases, adolescents who engage in disordered eating exhibit eating disorder symptoms (eg, restricting, vomiting, or use of laxatives, excessive exercise) at a lower frequency than is required for a formal diagnosis. Despite using these disordered eating behaviors at a lower frequency or for a shorter time than what is required for a clinical diagnosis and being considered "sub-clinical" (ie, less severe than a clinical eating disorder), disordered eating can still contribute to a myriad of health consequences. Specifically, clinical eating disorders and disordered eating disrupt nearly every bodily system. Not only do eating disorders represent the highest mortality rate of adolescents among all psychiatric conditions, eating disorders can also be associated with increased suicide risk and self-harming behaviors. Purging behaviors such as repetitive vomiting can place excessive strain on the esophagus, larynx, or voice box resulting in bleeding, tearing, or a ruptured esophagus. Other physical complications include cardiovascular problems, amenorrhea (ie, absence of menstrual cycle), gastrointestinal problems, tooth decay, reduced bone density, and impaired colon function. Electrolyte imbalances create an additional risk for individuals with eating disorders and may result in hospitalization. ${ }^{67}$ Unfortunately, the intended goal of achieving one's body ideal and feeling satisfaction is never actualized, as adolescents often find themselves obsessively consumed with the next bodily flaw or losing the next 5 pounds. ${ }^{68}$

Although being physically active is usually encouraged as a health-promoting behavior, exercising compulsively and excessively is a common purging strategy used to compensate for caloric intake or to change one's body weight, size, or shape. ${ }^{69}$ This tendency to develop disordered behaviors around exercise has received numerous labels including, but not limited to, exercise dependence, exercise abuse, exercise addiction, obligatory exercise, and overexercise. ${ }^{70}$ It is important to note that dysfunctional exercise involves both the amount and quality of exercise. That is, one's emotions around exercise and psychological mindset, including motivation for exercise, are as important as the quantity of exercise sessions. $^{71}$

Although exercise addiction is estimated to be around $3 \%$ of the general population, ${ }^{72}$ this prevalence increases to $30 \%-70 \%$ among clinical samples, ${ }^{73}$ and is estimated to range from $33 \%$ to almost $100 \%$ of inpatient eating disorder clients. ${ }^{74}$ In Dalle Grave et al's ${ }^{75}$ study, 39\% of clients with bulimia nervosa and $43 \%$ of clients with anorexia nervosa 
who used purging methods engaged in excessive exercise behaviors. Importantly, dysfunctional exercise during treatment and at the time of discharge is one of the strongest predictors for eating disorder relapse. ${ }^{76}$ Like other disordered eating behaviors, dysfunctional exercise is associated with physical and psychological health consequences, including poor concentration, fatigue, mood disturbances (eg, depression, irritability), overuse injuries (eg, stress fractures, pressure sores), social isolation, and impaired relationships. ${ }^{69}$

\section{Practical implications}

The importance of developing a healthy body image during adolescence should be emphasized given the associated health consequences. In light of the rising obesity rates among adolescents and the attention given to obesity as a public health priority, schools and communities tend to focus on obesity prevention and weight loss alone. However, interventions that emphasize these objectives without consideration for body image may have unintended consequences. For example, Irving and Neumark-Sztainer ${ }^{77}$ assert that many obesity interventions reinforce and normalize body dissatisfaction because of being overweight. In contrast, eating disorder interventions often emphasize self-acceptance and health at every size. Irving and Neumark-Sztainer recommend that interventions be integrated to address the broad spectrum of eating- and weight-related concerns (ie, obesity and eating disorders) in ways that equally promote a healthy body image. Neumark-Sztainer et $\mathrm{al}^{78}$ further suggest that interventions aimed to improve physical activity should avoid strategies that may have a negative impact on the body image of adolescents, such as unrealistic weight goals, critical weight-related comments, and weigh-ins. Instead, physical activity promotion should additionally include a means of increasing body satisfaction, especially when body satisfaction may buffer against symptoms associated with other mental health concerns in overweight adolescents, including depression, anxiety, and anger. ${ }^{79}$ Such integrated approaches not only acknowledge the full spectrum of eating- and weight-related concerns during adolescence, but also consider the preponderance of evidence suggesting that the point of intervention should include improving body perceptions versus weight status alone.

Grogan ${ }^{4}$ provided evidence supporting the effectiveness of programs aimed to promote a healthy body image among both adolescent boys and girls. Specifically, she discussed the importance of interventions that target the psychological correlates of poor body image (eg, low self-esteem), buffer the internalization of thin and muscular body ideals, reduce social comparisons, and address the influence of traditional gender roles on body image development. A review of 16 classroom-based body image programs in secondary schools revealed that the most effective programs were multisession interventions targeted toward younger adolescents between 12 years and 13 years of age that focused on media literacy, boosting self-esteem, and building peer support. ${ }^{80}$ An emerging body of research suggests that the strengths of social media, including its interactivity and networking capabilities, may be a valuable forum for promoting bodypositive messages. Perloff ${ }^{11}$ cautions that such social media interventions should be systematic, grounded in theory, tailored to the unique needs of the intended audience, and empirically evaluated.

Although promising, these interventions are not without limitations. For example, Yager et $\mathrm{a}^{80}$ noted that fewer than $20 \%$ of classroom-based body image programs had lasting effects. Specifically, most programs that yielded body image improvements immediately following the intervention did not sustain these improvements in the follow-up. Further, intervention programs have largely targeted adolescent girls, ${ }^{81,82}$ while intervention programs for adolescent boys are only beginning to be developed and evaluated. ${ }^{83}$ Finally, other researchers have emphasized the importance of attending to the design and target audience when developing body image interventions. For example, O'Dea ${ }^{84}$ found that two widely distributed body image education posters were perceived negatively by adolescent girls in that they aroused body image concerns and fueled social comparisons with girls shown in the poster. O'Dea emphasized the importance of first pilot-testing interventions on a small scale and soliciting the feedback from the intended audience. These efforts will help to guard against unintended consequences of a wellintended initiative.

A key example of an effective body image intervention is The Body Project developed for adolescent and young adult women with body image concerns ${ }^{85}$ Participants in this program critique the thin ideal through verbal, written, and behavioral activities to create cognitive dissonance with thin ideal messages and images and ultimately encourage positive perceptions of their own bodies. A growing body of evidence has demonstrated the effectiveness of a face-toface group and internet version of this program..$^{86,87}$ In their meta-analysis of eating disorder prevention programs, Stice et a ${ }^{88}$ found that the largest effects were identified for those that were delivered by expert interventionists to a selected target audience for which the intervention was designed; were offered only to women versus a mixed-gender group; 
emphasized cognitive-dissonance and body acceptance; and promoted active engagement across multiple sessions versus those that were merely didactic and psychoeducational. ${ }^{88}$ As a critical theme, tailoring the intervention to the specific participant demographic (eg, age, gender, developmental period) is essential in program design. These guidelines may be used and refined in the development of other intervention programs that show promise in improving body image among adolescents.

\section{Conclusion}

Adolescence is a critical period for body image development because of the various social, cultural, physical, and psychological changes occurring between the ages of 12 years and 18 years of age. The relationship between weight status and body image is complex, such that additional variables must be considered when explaining this association, including internalization of body ideals, weight-related pressures and concerns, and a range of social influences (eg, social comparison, fat talk, and weight-related teasing and bullying). Consequences associated with having a negative body image for adolescents include physical activity avoidance, eating disorders, and dysfunctional exercise. Therefore, promotion of a healthy body image should be integrated across all interventions aimed to address obesity, eating disorders, and other health-related concerns among adolescents.

\section{Disclosure}

The authors report no conflicts of interest in this work.

\section{References}

1. Markey CN. Why body image is important to adolescent development. J Youth Adolesc. 2010;39(12):1387-1391.

2. Cash TF. Body image: past, present, and future. Body Image. 2004;1(1): $1-5$.

3. Cash TF, Phillips KA, Santos MT, Hrabosky JI. Measuring 'negative body image': validation of the body image disturbance questionnaire in a nonclinical population. Body Image. 2004;1(4):363-372.

4. Grogan S. Promoting positive body image in males and females: contemporary issues and future directions. Sex Roles. 2010;63(9-10): 757-765.

5. Harriger JA, Thompson JK. Psychological consequences of obesity: weight bias and body image in overweight and obese youth. Int Rev Psychiatry. 2012;24(3):247-253.

6. Rohde P, Stice E, Marti CN. Development and predictive effects of eating disorder risk factors during adolescence: implications for prevention efforts. Int J Eat Disord. 2015;48(2):187-198.

7. Groesz LM, Levine MP, Murnen SK. The effect of experimental presentation of thin media images on body satisfaction: a meta-analytic review. Int J Eat Disord. 2002;31(1):1-16.

8. Ashikali E-M, Dittmar H, Ayers S. The effect of cosmetic surgery reality tv shows on adolescent girls' body image. Psychol Pop Media Cult. 2014;3(3):141-153.
9. Tiggemann M, Slater A. Netgirls: the internet, facebook, and body image concern in adolescent girls. Int J Eat Disord. 2013;46(6):630-633.

10. Meier EP, Gray J. Facebook photo activity associated with body image disturbance in adolescent girls. Cyberpsychol Behav Soc Netw. 2014; 17(4):199-206.

11. Perloff RM. Social media effects on young women's body image concerns: theoretical perspectives and an agenda for research. Sex Roles. 2014;71(11-12):363-377.

12. Schaefer MK, Salafia EHB. The connection of teasing by parents, siblings, and peers with girls' body dissatisfaction and boys' drive for muscularity: the role of social comparison as a mediator. Eat Behav. 2014;15(4):599-608.

13. Helfert $S$, Warschburger P. A prospective study on the impact of peer and parental pressure on body dissatisfaction in adolescent girls and boys. Body Image. 2011;8(2):101-109.

14. Neumark-Sztainer D, Bauer KW, Friend S, Hannan PJ, Story M, Berge JM. Family weight talk and dieting: how much do they matter for body dissatisfaction and disordered eating behaviors in adolescent girls? J Adolesc Health. 2010;47(3):270-276.

15. Webb HJ, Zimmer-Gembeck MJ. The role of friends and peers in adolescent body dissatisfaction: a review and critique of 15 years of research. J Res Adolesc. 2014;24(4):564-590.

16. Paxton SJ, Norris M, Wertheim EH, Durkin SJ, Anderson J. Body dissatisfaction, dating, and importance of thinness to attractiveness in adolescent girls. Sex Roles. 2005;53(9-10):663-675.

17. Lee JM, Appugliese D, Kaciroti N, Corwyn RF, Bradley RH, Lumeng JC. Weight status in young girls and the onset of puberty. Pediatrics. 2007;119(3):e624-e630.

18. Ackard DM, Peterson CB. Association between puberty and disordered eating, body image, and other psychological variables. Int J Eat Disord. 2001;29(2):187-194.

19. Nanu C, Tăut D, Băban A. Appearance esteem and weight esteem in adolescence. Are they different across age and gender? Cogn Brain Behav. 2013;17(3):189-200.

20. McCabe MP, Ricciardelli LA. A Longitudinal study of pubertal timing and extreme body change behaviors among adolescent boys and girls. Adolescence. 2004;39(153):145-166.

21. Erikson EH. Identity: Youth and Crisis. New York, NY: Norton; 1968.

22. Marcia JE. Development and validation of ego identity status. $J$ Pers Soc Psychol. 1966;3:551-558.

23. Balistreri E, Busch-Rossnagel NA, Geisinger KF. Development and preliminary validation of the ego identity process questionnaire. J Adolesc. 1995;18(2):179-192.

24. Wängqvist M, Frisén A. Swedish 18-year-olds' identity formation: associations with feelings about appearance and internalization of body ideals. J Adolesc. 2013;36(3):485-493.

25. Smolak L, Stein JA. A longitudinal investigation of gender role and muscle building in adolescent boys. Sex Roles. 2010;63(9-10):738-746.

26. Ogden CL, Carroll MD, Kit BK, Flegal KM. Prevalence of childhood and adult obesity in the United States, 2011-2012. J Am Med Assoc. 2014;311(8):806-814.

27. Calzo J, Sonneville KR, Haines J, Blood EA, Field AE, Austin SB. The development of associations among body mass index, body dissatisfaction, and weight and shape concern in adolescent boys and girls. J Adolesc Health. 2012;51:517-523.

28. Caccavale LJ, Farhat T, Iannotti RJ. Social engagement in adolescence moderates the association between weight status and body image. Body Image. 2012;9(2):221-226.

29. Quick V, Eisenberg ME, Bucchianeri MM, Neumark-Sztainer D. Prospective predictors of body dissatisfaction in young adults: 10-year longitudinal findings. Emerg Adulthood. 2013;1(4):271-282.

30. Bucchianeri MM, Arikian AJ, Hannan PJ, Eisenberg ME, NeumarkSztainer D. Body dissatisfaction from adolescence to young adulthood: findings from a 10-year longitudinal study. Body Image. 2013;10(1):1-7.

31. Thompson JK, van den Berg P, Roehrig M, Guarda AS, Heinberg LJ. The Sociocultural Attitudes Towards Appearance Scale-3 (SATAQ-3): development and validation. Int J Eat Disord. 2004;35(3):293-304. 
32. Lawler M, Nixon E. Body dissatisfaction among adolescent boys and girls: the effects of body mass, peer appearance culture and internalization of appearance ideals. J Youth Adolesc. 2011;40(1):59-71.

33. Knauss C, Paxton SJ, Alsaker FD. Relationships amongst body dissatisfaction, internalisation of the media body ideal and perceived pressure from media in adolescent girls and boys. Body Image. 2007;4(4): 353-360.

34. Petrie TA, Greenleaf C, Martin S. Biopsychosocial and physical correlates of middle school boys' and girls' body satisfaction. Sex Roles. 2010;63(9-10):631-644.

35. Mitchell SH, Petrie TA, Greenleaf CA, Martin SB. Moderators of the internalization - body dissatisfaction relationship in middle school girls. Body Image. 2012;9(4):431-440.

36. Jones DC, Crawford JK. Adolescent boys and body image: weight and muscularity concerns as dual pathways to body dissatisfaction. J Youth Adolesc. 2005;34(6):629-636.

37. Myers TA, Crowther JH. Social comparison as a predictor of body dissatisfaction: a meta-analytic review. J Abnorm Psychol. 2009;118(4) 683-698.

38. Rodgers RF, Paxton SJ, McLean SA. A biopsychosocial model of body image concerns and disordered eating in adolescent girls. JYouth Adolesc. 2014;43:814-823.

39. Sharpe H, Naumann U, Treasure J, Schmidt U. Is fat talking a causal risk factor for body dissatisfaction? A systematic review and meta-analysis. Int J Eat Disord. 2013;46(7):643-652.

40. Bauer KW, Bucchianeri MM, Neumark-Sztainer D. Mother-reported parental weight talk and adolescent girls' emotional health, weight control attempts, and disordered eating behaviors. J Eat Disord. 2013;1:45-45.

41. van Geel M, Vedder P, Tanilon J. Are overweight and obese youths more often bullied by their peers? A meta-analysis on the relation between weight status and bullying. Int J Obes (Lond). 2014;38(10): 1263-1267.

42. Lampard AM, MacLehose RF, Eisenberg ME, Neumark-Sztainer D, Davison KK. Weight-related teasing in the school environment: associations with psychosocial health and weight control practices among adolescent boys and girls. J Youth Adolesc. 2014;43(10):1770-1780.

43. Puhl RM, Luedicke J. Weight-based victimization among adolescents in the school setting: emotional reactions and coping behaviors. JYouth Adolesc. 2012;41(1):27-40.

44. Fox CL, Farrow CV. Global and physical self-esteem and body dissatisfaction as mediators of the relationship between weight status and being a victim of bullying. J Adolesc. 2009;32(5):1287-1301.

45. Whitt-Glover MC, Taylor WC, Floyd MF, Yore MM, Yancey AK, Matthews CE. Disparities in physical activity and sedentary behaviors among US children and adolescents: prevalence, correlates, and intervention implications. J Public Health Policy. 2009;30(Suppl 1): S309-S334.

46. Belcher BR, Berrigan D, Dodd KW, Emken BA, Chou C-P, Spruijt-Metz D. Physical activity in US youth: effect of race/ethnicity, age, gender, and weight status. Med Sci Sports Exerc. 2010;42(12): 2211-2221.

47. Janssen I, Katzmarzyk PT, Boyce WF, et al; Health Behaviour in School-Aged Children Obesity Working Group. Comparison of overweight and obesity prevalence in school-aged youth from 34 countries and their relationships with physical activity and dietary patterns. Obes Rev. 2005;6(2):123-132.

48. Neumark-Sztainer D, Paxton SJ, Hannan PJ, Haines J, Story M. Does body dissatisfaction matter? J Adolesc Health. 2006;39:244-251.

49. Stankov I, Olds T, Cargo M. Overweight and obese adolescents: what turns them off physical activity? Int J Behav Nutr Phys Act. 2012;9:53-53.

50. Greenleaf C, Petrie TA, Martin SB. Relationship of weight-based teasing and adolescents' psychological well-being and physical health. J Sch Health. 2014;84(1):49-55.

51. Losekam S, Goetzky B, Kraeling S, Rief W, Hilbert A. Physical activity in normal-weight and overweight youth: associations with weight teasing and self-efficacy. Obes Facts. 2010;3(4):239-244.
52. Jensen CD, Steele RG. Brief report: body dissatisfaction, weight criticism, and self-reported physical activity in preadolescent children. J Pediatr Psychol. 2009;34(8):822-826.

53. Monteiro Gaspar MJ, Amaral TF, Oliveira BMPM, Borges N. Protective effect of physical activity on dissatisfaction with body image in children - a cross-sectional study. Psychol Sport Exercise. 2011;12(5): 563-569.

54. Goldfield GS, Mallory R, Parker T, et al. Effects of modifying physical activity and sedentary behavior on psychosocial adjustment in overweight/obese children. J Pediatr Psychol. 2007;32(7):783-793.

55. Huang JS, Norman GJ, Zabinski MF, Calfas K, Patrick K. Body image and self-esteem among adolescents undergoing an intervention targeting dietary and physical activity behaviors. J Adolesc Health. 2007;40(3):245-251.

56. Lindwall M, Lindgren E-C. The effects of a 6-month exercise intervention programme on physical self-perceptions and social physique anxiety in non-physically active adolescent Swedish girls. Psychol Sport Exerc. 2005;6(6):643-658.

57. Wertheim EH, Koerner J, Paxton SJ. Longitudinal predictors of restrictive eating and bulimic tendencies in three different age groups of adolescent girls. J Youth Adolesc. 2001;30(1):69-81.

58. Stice E, Shaw HE. Role of body dissatisfaction in the onset and maintenance of eating pathology: a synthesis of research findings. J Psychosom Res. 2002;53(5):985-993.

59. Heywood S, McCabe MP. Negative affect as a mediator between body dissatisfaction and extreme weight loss and muscle gain behaviors. J Health Psychol. 2006;11(6):833-844.

60. Brechan I, Kvalem IL. Relationship between body dissatisfaction and disordered eating: mediating role of self-esteem and depression. Eat Behav. 2015;17:49-58.

61. American Psychiatric Association. Diagnostic and Statistical Manual of Mental Disorders. Fifth ed. Washington, DC: American Psychiatric Association; 2013.

62. Reel JJ. The relationship between exercise and eating disorders: a doubleedged sword. In: Andersen MB, Hanrahan SJ, editors. Doing Exercise Psychology. Champaign, IL, US: Human Kinetics; 2015:259-273.

63. De Young KP, Anderson DA. The importance of the function of exercise in the relationship between obligatory exercise and eating and body image concerns. Eat Behav. 2010;11(1):62-64.

64. Duarte C, Pinto-Gouveia J, Ferreira C. Escaping from body image shame and harsh self-criticism: exploration of underlying mechanisms of binge eating. Eat Behav. 2014;15(4):638-643.

65. Croll JK, Neumark-Sztainer D, Story M, Ireland M. Prevalence and risk and protective factors related to disordered eating behaviors among adolescents: relationship to gender and ethnicity. J Adolesc Health. 2002;31(2):166-175.

66. Radtke T, Kaklamanou D, Scholz U, Hornung R, Armitage CJ. Are diet-specific compensatory health beliefs predictive of dieting intentions and behaviour? Appetite. 2014;76:36-43.

67. Katzman DK. Medical complications in adolescents with anorexia nervosa: a review of the literature. Int J Eat Disord. 2005;37(Suppl): S52-S59.

68. Burt NM, Boddy LE, Bridgett DJ. Contribution of temperament to eating disorder symptoms in emerging adulthood: additive and interactive effects. Eat Behav. 2015;18:30-35.

69. Hausenblas HA, Cook BJ, Chittester NI. Can exercise treat eating disorders? Exerc Sport Sci Rev. 2008;36(1):43-47.

70. Calogero RM, Pedrotty-Stump KN. Incorporating exercise into eating disorder treatment and recovery: cultivating a mindful approach. In: Maine M, McGilley BH, Bunnell DW, editors. Treatment of Eating Disorders: Bridging the Research-Practice Gap. San Diego, CA, US: Elsevier Academic Press; 2010:425-441.

71. Taranis L, Meyer C. Associations between specific components of compulsive exercise and eating-disordered cognitions and behaviors among young women. Int J Eat Disord. 2011;44(5):452-458.

72. Sussman S, Lisha N, Griffiths M. Prevalence of the addictions: a problem of the majority or the minority? Eval Health Prof. 2011;34(1):3-56. 
73. Mond JM, Calogero RM. Excessive exercise in eating disorder patients and in healthy women. Aust N Z J Psychiatry. 2009;43(3):227-234.

74. Kiezebrink K, Campbell D, Mann E, Blundell J. Similarities and differences between excessive exercising anorexia nervosa patients compared with DSM-IV defined anorexia nervosa subtypes. Eat Weight Disord. 2009; 14(4):e199-e204.

75. Dalle Grave R, Calugi S, Marchesini G. Compulsive exercise to control shape or weight in eating disorders: prevalence, associated features, and treatment outcome. Compr Psychiatry. 2008;49(4):346-352.

76. Steinglass JE, Sysko R, Glasofer D, Albano AM, Simpson HB, Walsh BT. Rationale for the application of exposure and response prevention to the treatment of anorexia nervosa. Int J Eat Disord. 2011; 44(2):134-141.

77. Irving LM, Neumark-Sztainer D. Integrating the prevention of eating disorders and obesity: feasible or futile? Prev Med. 2002;34(3): 299-309.

78. Neumark-Sztainer D, Goeden C, Story M, Wall M. Associations between body satisfaction and physical activity in adolescents: implications for programs aimed at preventing a broad spectrum of weight-related disorders. Eat Disord. 2004;12(2):125-137.

79. Cromley T, Knatz S, Rockwell R, Neumark-Sztainer D, Story M, Boutelle K. Relationships between body satisfaction and psychological functioning and weight-related cognitions and behaviors in overweight adolescents. J Adolesc Health. 2012;50(6):651-653.

80. Yager Z, Diedrichs PC, Ricciardelli LA, Halliwell E. What works in secondary schools? A systematic review of classroom-based body image programs. Body Image. 2013;10(3):271-281.
81. Richardson SM, Paxton SJ. An evaluation of a body image intervention based on risk factors for body dissatisfaction: a controlled study with adolescent girls. Int J Eat Disord. 2010;43(2):112-122.

82. Halliwell E, Diedrichs PC. Testing a dissonance body image intervention among young girls. Health Psychol. 2014;33(2):201-204.

83. McCabe MP, Ricciardelli LA, Karantzas G. Impact of a healthy body image program among adolescent boys on body image, negative affect, and body change strategies. Body Image. 2010;7(2):117-123.

84. O'Dea J. Can body image education programs be harmful to adolescent females? Eat Disord. 2002;10(1):1-13.

85. Stice E, Shaw H, Burton E, Wade E. Dissonance and healthy weight eating disorder prevention programs: a randomized efficacy trial. $J$ Consult Clin Psychol. 2006;74(2):263-275.

86. Stice E, Rohde P, Durant S, Shaw H. A preliminary trial of a prototype internet dissonance-based eating disorder prevention program for young women with body image concerns. J Consult Clin Psychol. 2012;80(5): 907-916.

87. Stice E, Butryn ML, Rohde P, Shaw H, Marti CN. An effectiveness trial of a new enhanced dissonance eating disorder prevention program among female college students. Behav Res Ther. 2013;51(12):862-871.

88. Stice E, Shaw H, Marti CN. A meta-analytic review of eating disorder prevention programs: encouraging findings. Annu Rev Clin Psychol. 2007;3:207-231.
Adolescent Health, Medicine and Therapeutics

\section{Publish your work in this journal}

Adolescent Health, Medicine and Therapeutics is an international, peer-reviewed, open access journal focusing on health, pathology, and treatment issues specific to the adolescent age group. All aspects of health maintenance, preventative measures and disease treatment interventions are addressed within the journal and practitioners from

\section{Dovepress}

all disciplines are invited to submit their work as well as healthcare researchers and patient support groups.. The manuscript management system is completely online and includes a very quick and fair peerreview system. Visit http://www.dovepress.com/testimonials.php to read real quotes from published authors. 